\title{
Acute Dacryocystitis with Abscess: Endonasal Dacryocystorhinostomy, the Primary Treatment of Choice
}

\author{
Sudhir M Naik, Sarika S Naik
}

\begin{abstract}
Background/objectives: Acute dacryocystitis, or inflammation of the lacrimal sac with abscess, is almost always secondary to nasolacrimal duct obstruction. The standard practice for treatment is incision and drainage because of concerns about the risks of exacerbation and spread of infection. Here, we tried to evaluate primary endoscopic dacryocystorhinostomy (EnDCR) as a treatment for acute dacryocystitis with abscess formation.
\end{abstract}

Materials and methods: This is comparative case series analysis study done during the study period of 54 months from January 2007 to May 2011. A total of 46 cases of acute dacryocystitis with lacrimal abscess managed were included in the study. Twenty-one cases were operated primarily with EnDCR. Rest of the 25 cases was managed conventionally by incision and drainage and later by an external DCR.

Results: Swelling disappeared intraoperatively in all EnDCR cases while medial canthal edema and erythema completely reduced within 2 to 3 days postoperatively. While in incision and drainage swelling disappeared partially intraoperatively and repeated draining was needed on the 2 nd and 3rd day.

The mean visual analog scale (VAS) score on first postoperative day was 3.14 in group $A$ and was 4.64 in group B. Group A had faster pain relief with $95.23 \%$ improvement in epiphora while group B had slower pain relief but epiphora remained. Mean intraoperative blood was $65 \mathrm{ml}$ in group A and minimal in group $B$.

Conclusion: Primary EnDCR is successful as a procedure of choice for acute dacryocystitis with abscess preventing further episodes of abscess formation and epiphora in the patients. We recommend EnDCR as the treatment of choice for acute dacryocystitis with lacrimal abscess.

Keywords: Dacryocystitis, Lacrimal abscess, Incision and drainage, Endoscopic dacryocystorhinostomy.

How to cite this article: Naik SM, Naik SS. Acute Dacryocystitis with Abscess: Endonasal Dacryocystorhinostomy, the Primary Treatment of Choice. Clin Rhinol An Int J 2012;5(3):107-113.

Source of support: Nil

Conflict of interest: None declared

\section{INTRODUCTION}

Acute dacryocystitis, or inflammation of the lacrimal sac with lacrimal abscess, is almost always secondary to nasolacrimal duct obstruction. ${ }^{1}$ It usually results from infection by Staphylococcus aureus or $\beta$-hemolytic Streptococcus and presents as epiphora, swelling and redness at the medial canthus of the eye. ${ }^{2}$ In untreated cases the infection may spread to surrounding tissues causing preseptal or orbital cellulitis or abscess formation. ${ }^{2}$
Ten percent of adults aged 40 years or older have obstruction of the lacrimal drainage system and this percentage increases with age. ${ }^{3}$ In India, the incidences are more in females as cosmetics especially kajol may lead to partial or complete blockage of the draining system. ${ }^{4,5}$ Acute dacryocystitis is an extremely painful and a slow to resolve condition even with a systemic antibiotic therapy. ${ }^{6}$ The conventional treatment of acute dacryocystitis with abscess formation includes warm compresses, systemic antibiotics, percutaneous drainage and external dacryocystorhinostomy (ExDCR) after resolution of acute infection. ${ }^{7}$ This may result in fistula formation or the risk of recurrent infection before DCR can be performed and prolonged use of systemic antibiotics. ${ }^{8}$ In addition, ExDCR results in a visible scar and can disrupt the lacrimal pump mechanism. ${ }^{8}$

Primary endoscopic dacryocystorhinostomy (EnDCR) in acute dacryocystitis with abscess has advantages over standard treatment with rapid improvement in pain and inflammation, and economic benefits of reduced patient stay with the need for later readmission and DCR as definitive treatment. ${ }^{9}$ Also, the procedure is difficult as comparatively more bleeding is seen with inflamed nasal mucosal membranes than with elective cases. ${ }^{10}$ The present study was done to prospectively evaluate primary endoscopic DCR as a treatment for acute dacryocystitis with abscess formation. ${ }^{10}$

The standard practice for the treatment of acute purulent dacryocystitis has not included surgical intervention because of concerns about the risks of exacerbation and spread of infection. ${ }^{11}$ So ExDCR is usually performed after the resolution of acute infection through the use of warm compresses, systemic antibiotics and percutaneous abscess drainage. ${ }^{6}$ This treatment plan, however, may result in several complications, such as prolonged or recurrent infection, adverse antibiotic effects because of long-term use, cutaneous scar or fistula formation, and failure of lacrimal system reconstruction because of scarring or granuloma formation in the lacrimal sac. ${ }^{11}$

EnDCR with lasers are also proven alternatives for the conventional incision and drainage but the results are short lived unless a wide rhinostome is created using drills and punches. ${ }^{9,12}$ Even laser-assisted EnDCR are less effective as treatment of chronic dacryocystitis because of the small size of the ostia created and the ostial fibrosis and stenosis resulting from the heat generated by bone and mucosa 
ablation with a holmium:yttrium-aluminum-garnet (holmium:YAG) and potassium titanyl phosphate (KTP) laser. ${ }^{9,12}$ EnDCR has added advantage of minor traumatization, lacrimal pump function being preserved, reduction in time of surgery, minimal morbidity and simultaneous treatment of sinonasal diseases. ${ }^{13}$

\section{MATERIALS AND METHODS}

This is comparative case series analysis study done in our medical college, hospital during the study period of 54 months from January 2007 to May 2011. Forty-six cases of acute dacryocystitis with lacrimal abscess managed in our intuition were included in the study. Twenty-one cases were operated primarily with EnDCR. Rest of the 25 cases were managed conventionally by incision and drainage and later by an external approach of DCR. All cases of acute dacryocystitis with lacrimal abscess managed with EnDCR or conventional way were included while all cases of EnDCR done for chronic dacryocystitis were excluded (Figs 1 to 6). Baseline investigations were done along with CT scan PNS (Figs 7 and 8). All the 21 cases in group A
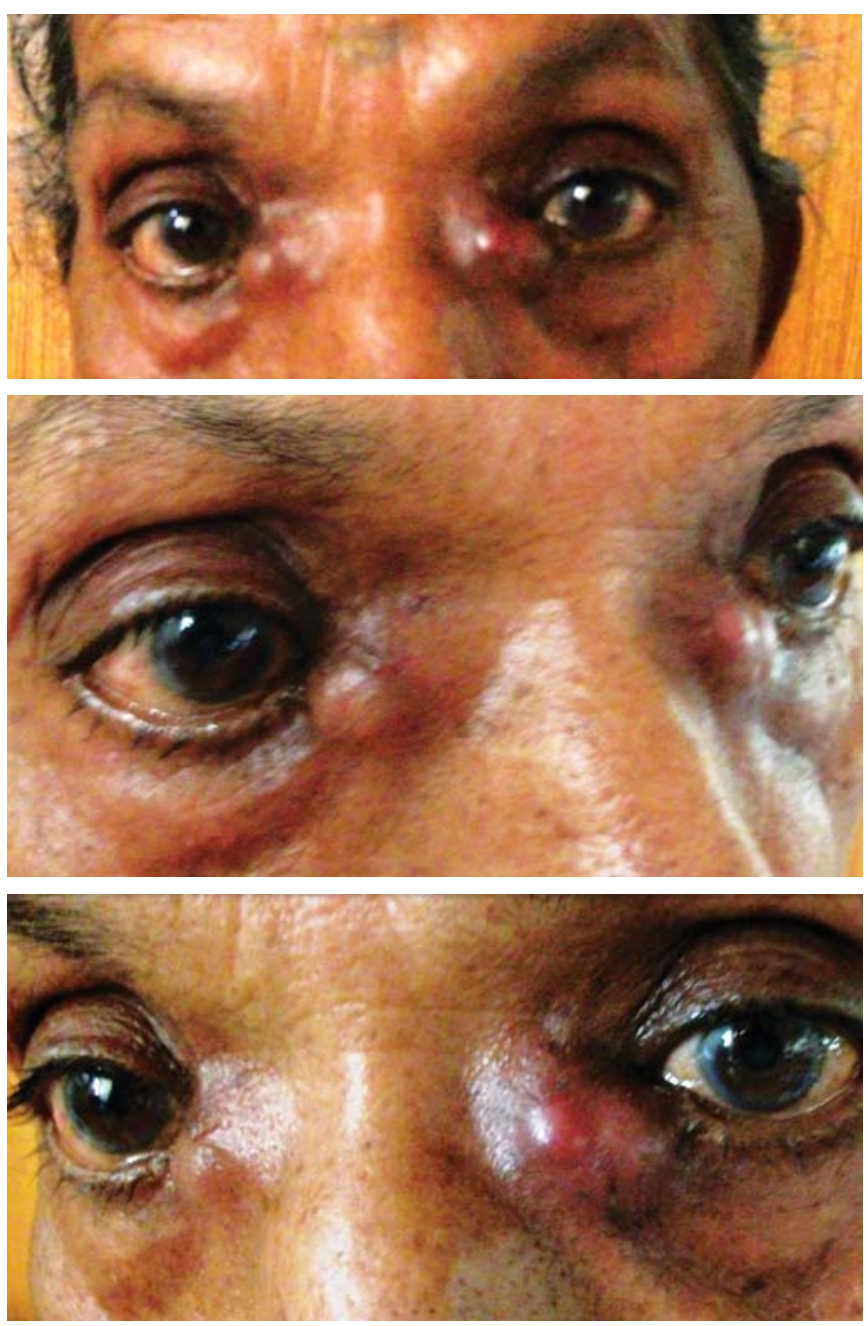

Fig. 1: Bilateral acute dacryocystitis with abscess in an old woman before EnDCR
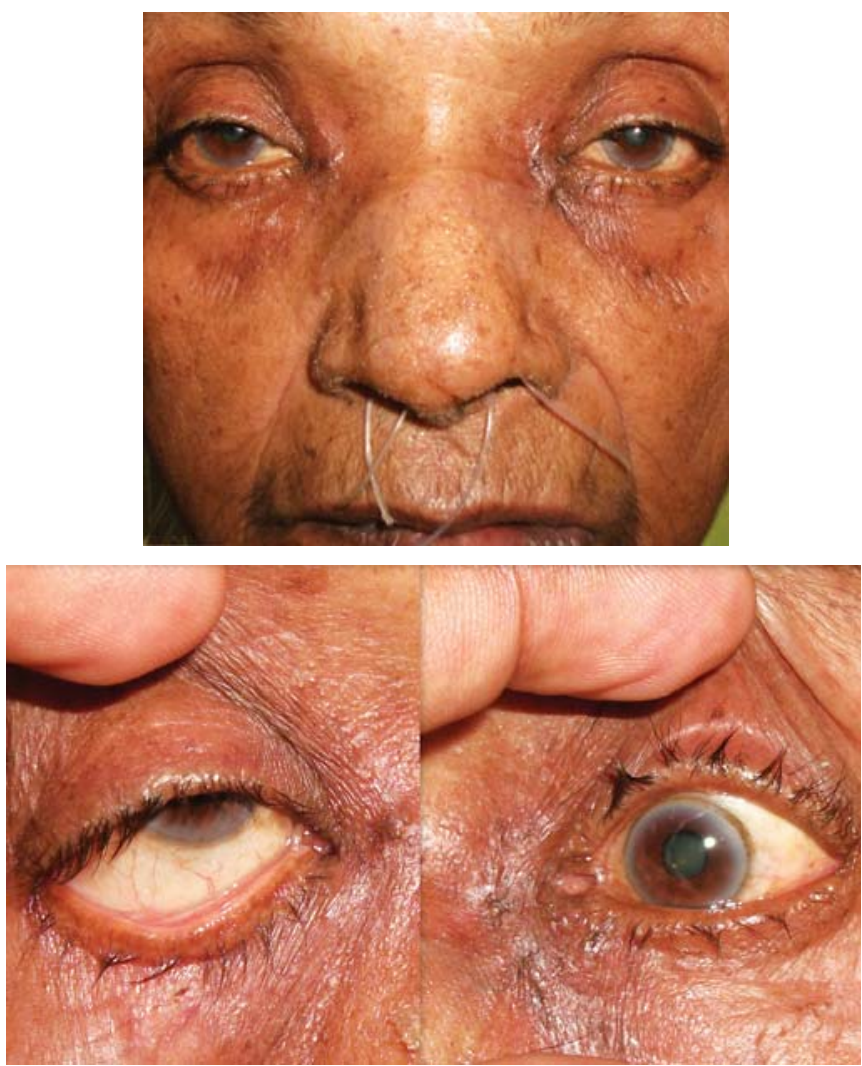

Fig. 2: EnDCR done with silicon tube stent in the same patient 1 week later
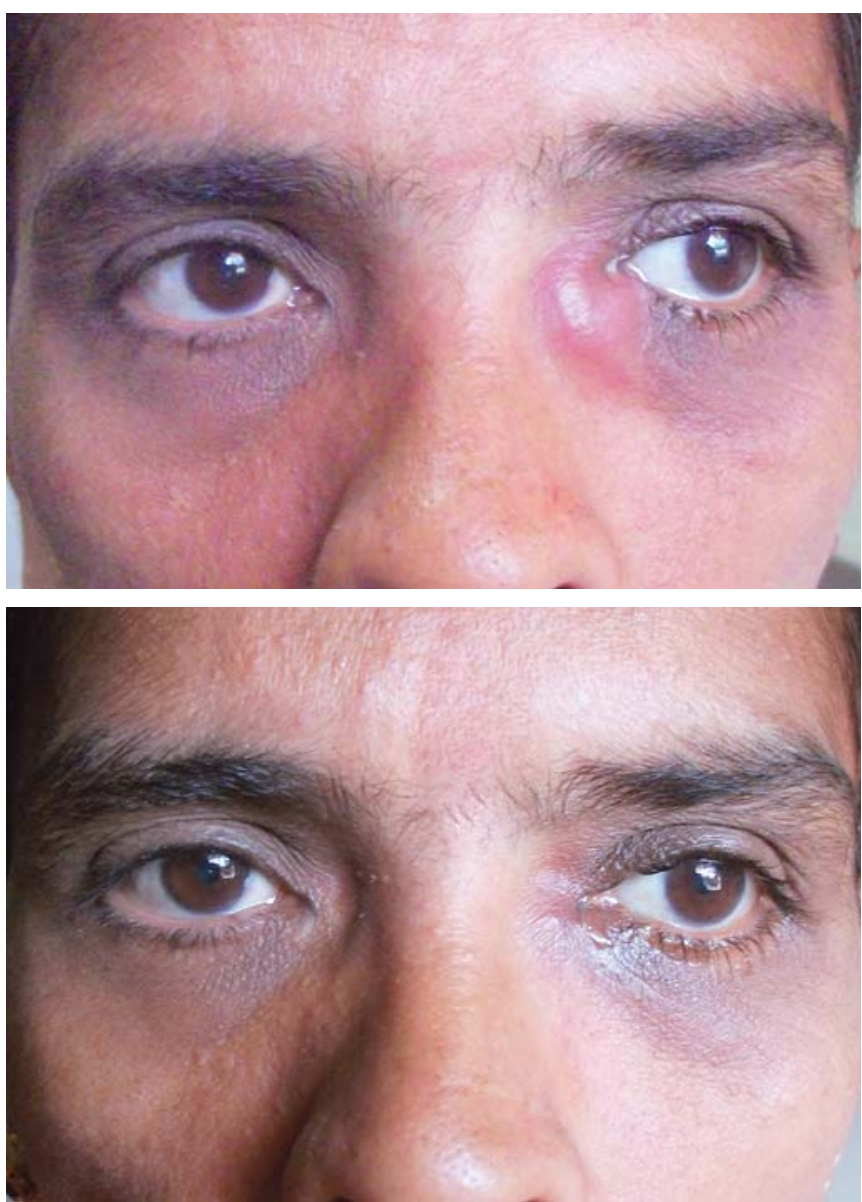

Fig. 3: Left acute dacryocystitis with abscess before and after EnDCR 

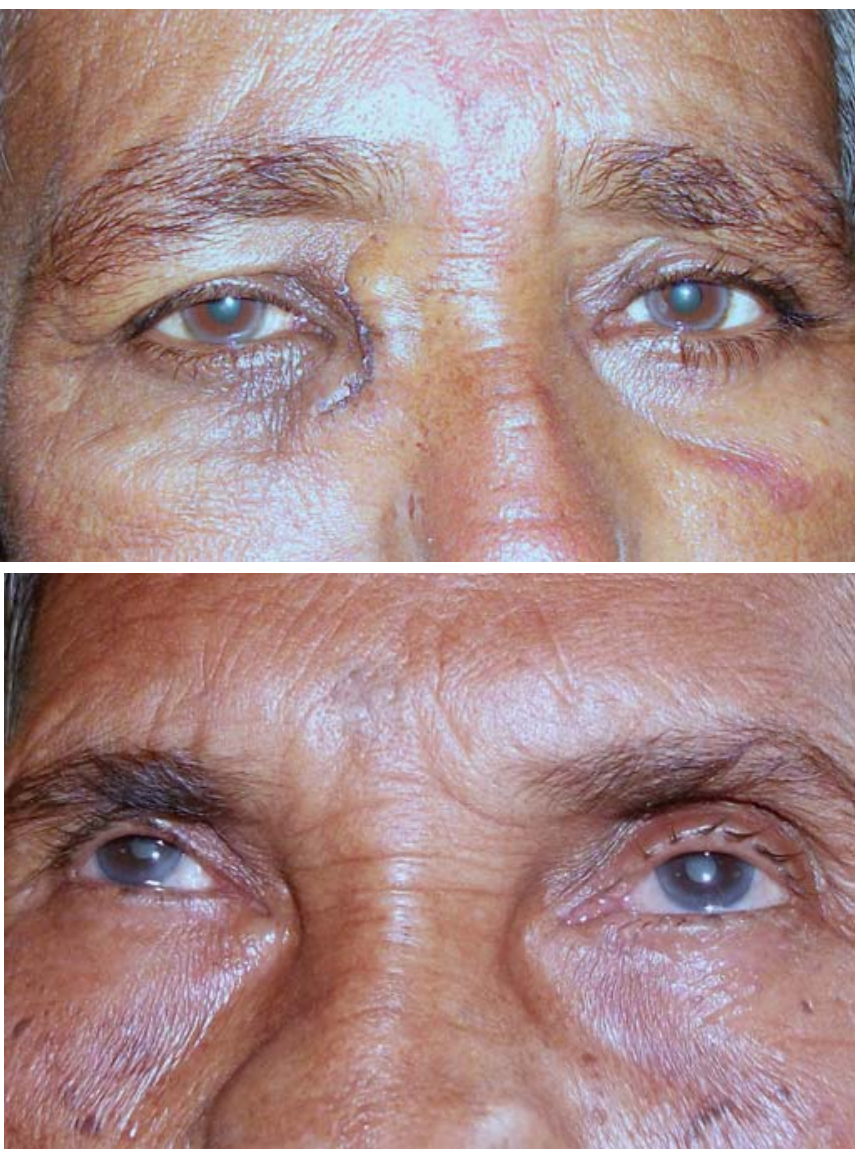

Fig. 4: Comparison of results of external DCR and EnDCR
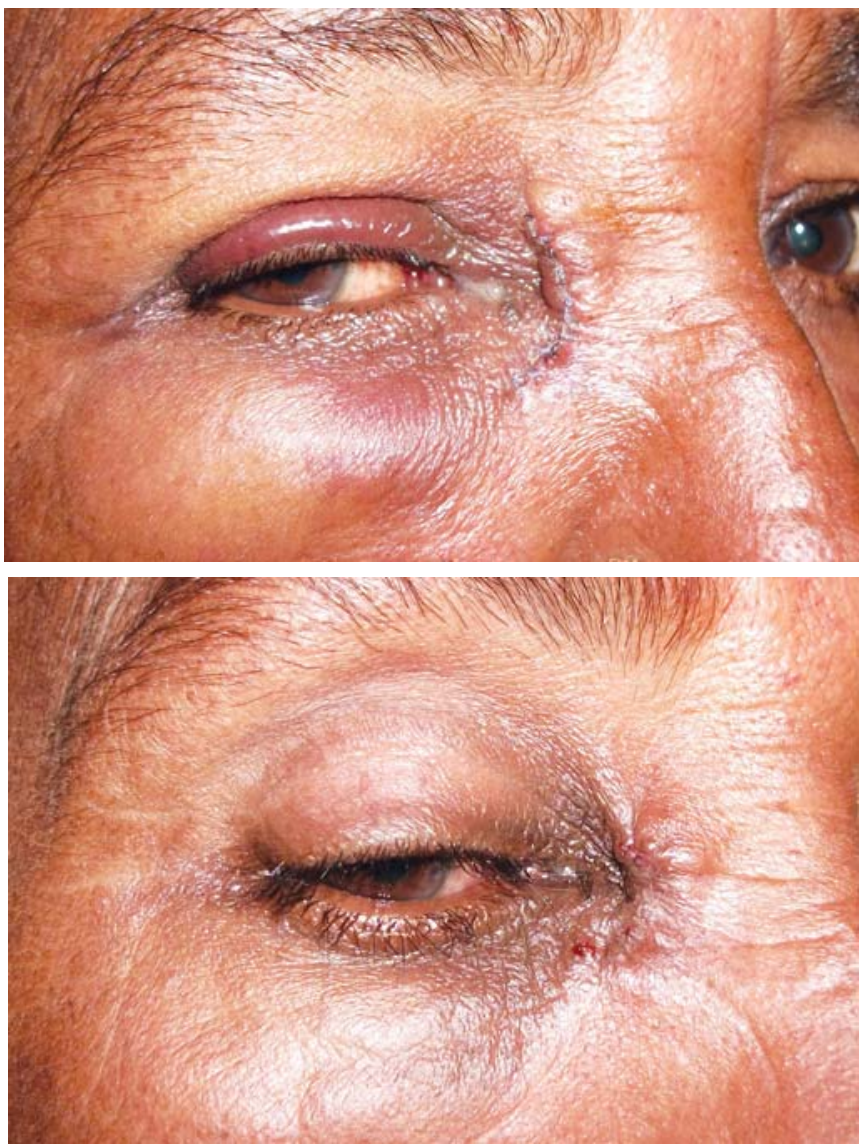

Fig. 5: External DCR at 3rd and 8th postoperative days
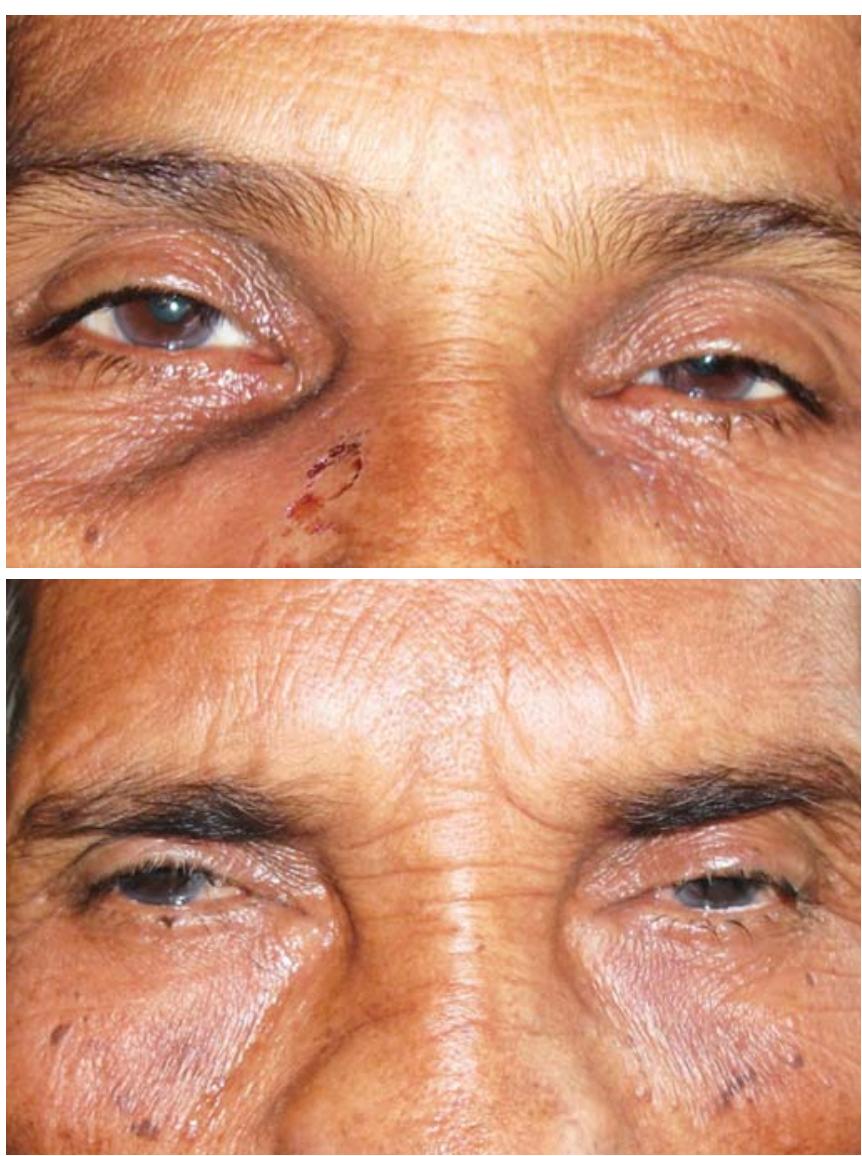

Fig. 6: Good results with EnDCR seen in two patients for acute dacryocystitis with abscess

were treated with EnDCR under general anesthesia; cases operated on local anesthesia were excluded. All the 25 patients in group B were treated by incision and drainage under local anesthesia. All cases were followed up for 3 to 6 months. Cases lost early were excluded and no cases of lacrimal sac tumors were seen during the study.

Any significant septal or turbinate abnormality was corrected endoscopically before DCR. Preoperative intravenous antibiotic was started on the day of admission, with nasal decongestants and analgesics. EnDCR was performed under general anesthesia using DCR punch of $2 \mathrm{~mm}, 3 \mathrm{~mm}$ straight and curved. Intranasal infiltration was given in submucosal plane anterior to anterior end of middle turbinate. Mucosal flap was elevated using an elevator with suctioning, as relatively more bleeding is there because of mucosal inflammation in acutely infected settings, and bipolar intranasal cautery was used to reduce mucosal bleed. Bony landmarks were identified, and bone over the medial wall of lacrimal sac was removed using these bony landmarks like anterior end of middle turbinate and posterior margin of frontal process of maxilla (Fig. 9).

The medial wall of lacrimal sac was incised to drain out the pus, and sac wall was punched out. Silicone tubal stent was introduced from the punctum and knotted in the nasal cavity. Small framycetin ribbon pack was kept in situ and 

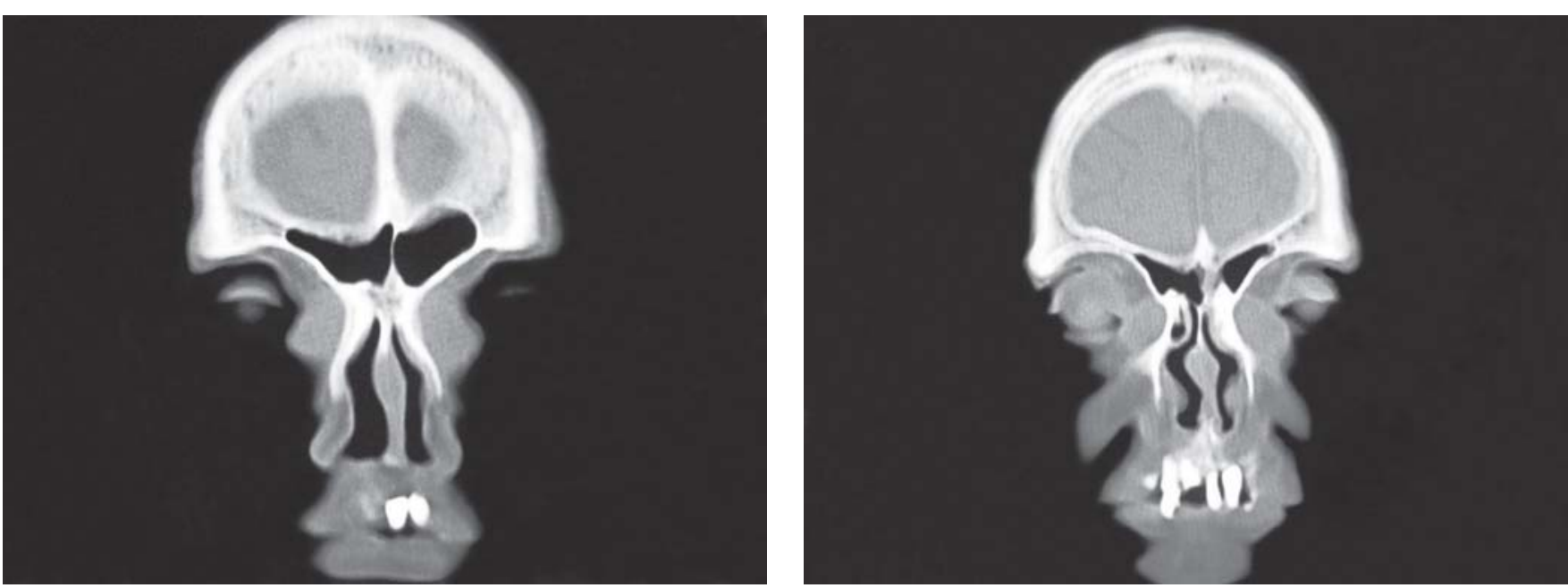

Fig. 7: Coronal cuts of lacrimal bilateral abscess
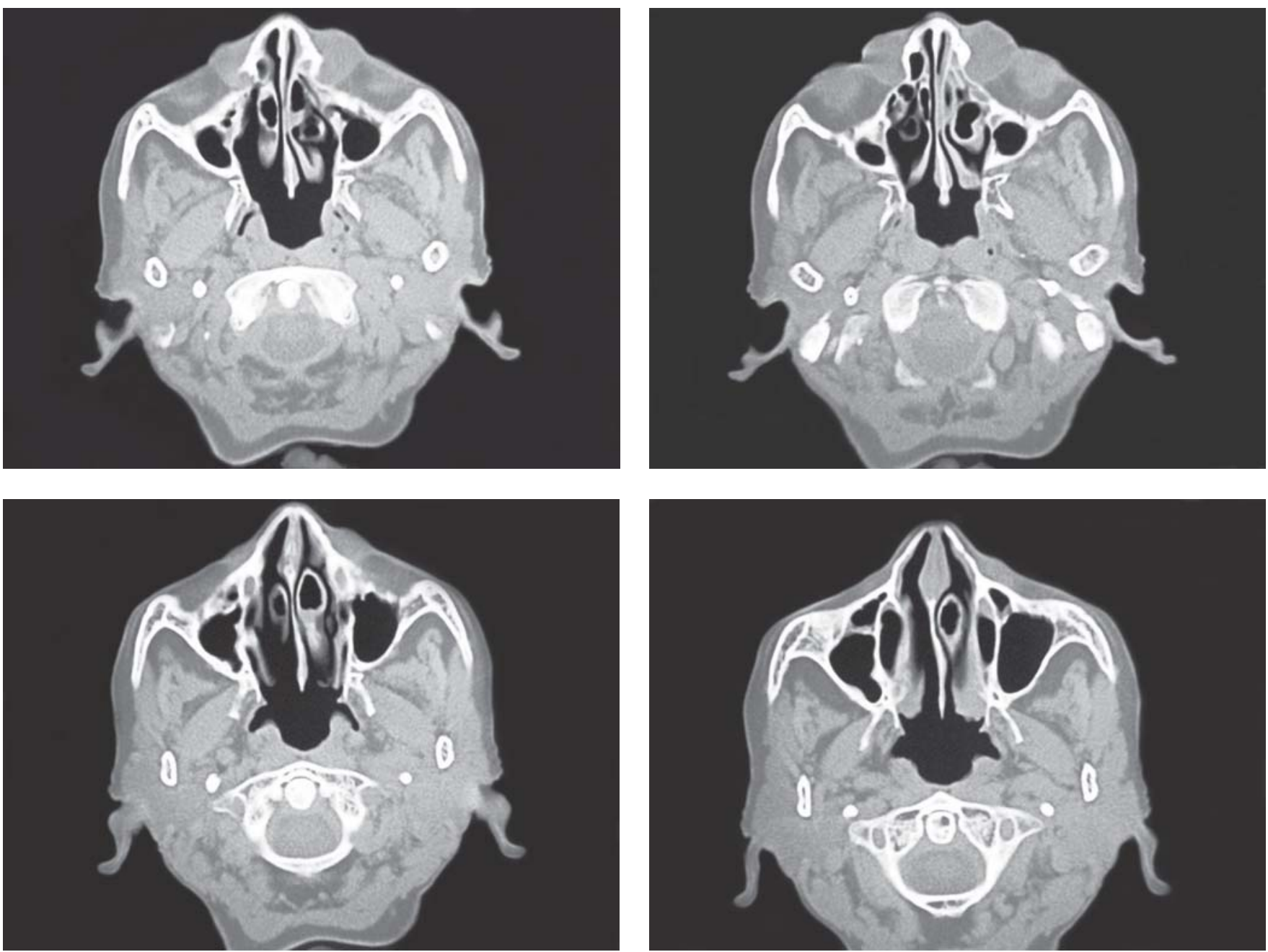

Fig. 8: Axial cuts of bilateral lacrimal abscess

removed after 24 hours. Intravenous antibiotics were continued, and the patient was discharged the next day. Oral antibiotics and anti-inflammatory drugs were continued for further 8 days along with antibiotic eye drops and nasal decongestant drops. The stent was placed for 3 months.
All the 25 cases in group B were treated by incision and drainage with supra-, infraorbital and lateral nasal wall infiltration, which was done using lidocaine 2\% with 1:100,000 adrenaline. Abscess drainage was repeated on 2nd and 3rd day. 


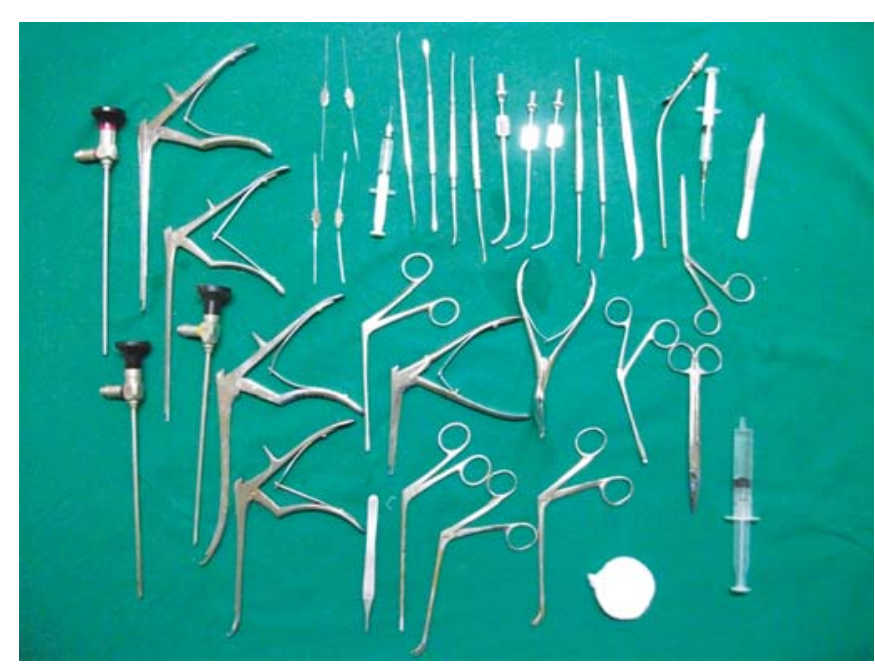

Fig. 9: Instruments set used for EnDCR

\section{RESULTS}

A total of 46 patients including 19 males and 27 females were included in the study. The mean age in group A was 57.4 years and 52.5 in group B. Bilateral abscesses were seen in four cases in group A and three cases in group B. Incision and drainage earlier was done in seven cases in group A and six cases in group B. EnDCR was attempted previously in six cases in group A and one case in group B. The mean previous episodes of swellings were 2.42 in group A and 2.44 in the other. Lesser hospital stay seen in EnDCR group with mean of 1.33 days compared to 5.28 in the other.

EnDCR was done in all the group A patients under general anesthesia with silicone tube stent. Incision and drainage was done in all the 25 cases in group $B$ with surface anesthesia 15\% lidocaine spray and local infiltration. Swelling disappeared intraoperatively in all group A cases while medial canthal edema and erythema completely reduced within 2 to 3 days postoperatively. While in group B swelling disappeared partially intraoperatively and repeated draining was needed on the 2nd and 3rd day. Medial canthal edema and erythema took a week to disappear. Patency on syringing was seen immediately after EnDCR later the stent was placed for 3 months in group A and patency was tested at 3 and $6 \mathrm{~m}$ after stent removal. Twenty patients showed patency on syringing at 3 and 6 months. No syringing was done in group B.

The mean visual analog scale (VAS) score on first postoperative day was 3.14 in group A which was marginally higher in group B, i.e. 4.64. Group A patients had dramatic pain relief in 2 days but group B patients had slow pain relief over a week. Improvement in epiphora was seen in $95.23 \%$ of group A patients and none in group B. Mean intraoperative blood loss was $65 \mathrm{ml}$ in group A and minimal in group B.

Coexistent nasal pathology were corrected in group A like concha bulloplasty in seven cases, septoplasty in three cases, sinus pathology in five cases and polyps removed in one case. All the cases were followed up for 6 months, more complications were seen in group B like recurrence of abscess in two cases, postoperative fistula in four cases and external scar in 23 cases but no such problems in group A.

Drastic improvement in epiphora, immediate resolution of abscess, no complication with lesser hospital stay was seen in group A cases treated with EnDCR, so we recommend EnDCR as the primary treatment of choice in acute dacryocystitis with abscess. Silicon tube stent was placed in all cases and removed at 3 months follow-up. Punctum dilation and probing was done in all cases as most of them stenosed making the stents necessary in all cases.

Extensive literature research reported no studies on acute dacryocystitis with abscess treated with EnDCR and various results of studies done by different authors show success rates as comparable to external DCR (Graph 1).

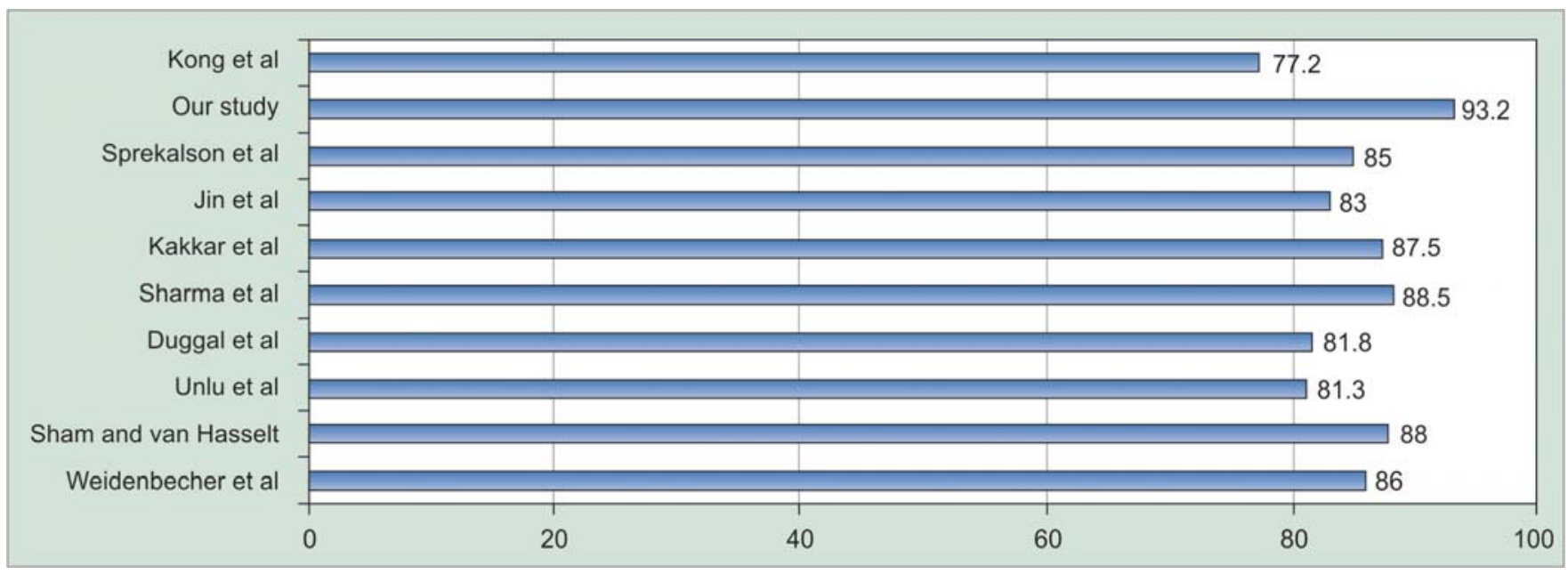

Graph 1: Comparison of EnDCR success rates 


\section{DISCUSSION}

Acute dacryocystitis commonly presents as preseptal cellulitis as lacrimal sac lies anterior to the orbital septum and hence infection localizes in the preseptal space. ${ }^{14}$ Acute dacryocystitis is an ophthalmic emergency that can cause orbital cellulitis with abscess formation, and even vision loss, if left untreated. ${ }^{14}$

Dacryocystorhinostomy by external approach (ExDCR) is contraindicated in acute dacryocystitis with abscess because of the risk of spreading infection through tissue planes, septicemia and exacerbating inflammation. ${ }^{15,16}$

EnDCR gives the preference of approaching the lacrimal sac through the noninfected tissue planes and can prevent spread of infection and prevents external scar and can be practiced as the primary treatment of choice for lacrimal abscsses. ${ }^{10}$ Earlier EnDCR was tried in cases where acute dacryocystitis were resistant to antibiotics. ${ }^{17}$

Results in our study was similar to that done by Duggal et al where all the patients with abscess had immediate resolution with EnDCR and no recurrence for the next 6 months of follow-up, with minimal hospital stay and absent external scar compared to the group treated conventionally with incision and drainage. ${ }^{10}$

The external scars seen in incision and drainage are absent making it a cosmetically superior approach and also functionally better as lacrimal pump is not damaged as orbicularis oculi is not incised. ${ }^{18}$ Also coexistent middle turbinate anomalies causing obstructions to the flow of lacrimal fluid can be corrected. ${ }^{17}$

Duggal et al in their study on 11 cases of acute dacryocystitis with abscess treated by EnDCR found a success rate of $81.8 \%$ which was less compared to other studies. ${ }^{10}$ The lesser success rates were due to scarring and obliteration of lacrimal sac abscess cavity after surgical drainage and may reflect the presence of acute inflammation promoting restenosis. ${ }^{8-10}$

Use of silicone tube stent following EnDCR for acute dacryocystitis abscess are not present in literature and its use in chronic dacryocystitis is controversial. ${ }^{19}$ Some studies report higher rates of failure caused by the stents due to damage to the mucosa of the canaliculi and increased granulation formation resulting in rhinostomal restenosis. ${ }^{20}$ Duggal et al in their study did not use stents as they found the sac was edematous and cellulitis had set in causing the maneuvering of stent difficult and led to false passages. ${ }^{10}$

Subbaiah et al in their study on nine cases of acquired lacrimal abscess found EnDCR to be very effective and cessation of epiphora and closure of the fistula was seen in all the cases after the surgery. ${ }^{21}$ All the lacrimal fistulas in the study were as a result of improperly treated lacrimal abscesses by conventional incision and drainage. ${ }^{21}$
Also, incision and drainage and ExDCR in acute cases can cause damage to the sac with added infection from the acute infection together cause fibrosis and granuloma formation in the lacrimal sac thereby reducing the rhinostomal patency later. ${ }^{22}$ Wencan et al and Lee and Woog in separate studies advocated EnDCR as primary treatment of choice for acute purulent dacryocystitis which are consistent with the results in our study. ${ }^{9}$ Wencan et al found 90\% success with EnDCR with silicon tube stents after removal at 12 months done for acute dacryocystitis. ${ }^{9}$

Failures in EnDCR are usually due to rhinostome occlusion by membrane or synechiae formation between rhinostome and the middle turbinate. ${ }^{23}$ Attempts to improve results led to silicone tube stent being placed or special Pyrex tube placed across the lacrimal sac and nasal mucosal anastomosis to prevent recurrent obstruction. ${ }^{24,25}$ Whenever, there is absence of canalicular function, either due to obstruction less than $8 \mathrm{~mm}$ from the puncta or to lacrimal pump failure, conjunctivo-canalicular DCR with Lester Jones tube insertion has been done for relief of epiphora. ${ }^{24,25}$ Recently balloon dacryocystoplasty is done in adults with partial nasolacrimal duct obstruction who do not exhibit signs of chronic infection. ${ }^{24,25}$

In our study, the highly edematous mucous membrane due to acute inflammation and pre-existent stenosis of the common canaliculus was prudently managed by endonasal bipolar cautery and silicon tube stents used in all the cases.

\section{CONCLUSION}

Primary EnDCR has proven highly successful as a procedure of choice for acute dacryocystitis with abscess preventing further episodes of abscess formation and also relieving the pre-existing symptoms of epiphora in most patients.

EnDCR has over-ranked the conventional methods of incision and drainage with medical line of management for lacrimal abscesses. We recommend EnDCR as the treatment of choice for acute dacryocystitis with lacrimal abscess.

\section{REFERENCES}

1. Nerad JA, Kersten RC, Neuhaus RW, et al. Basic and clinical science course: Orbit, eyelids and lacrimal system. San Francisco, CA: American Academy of Ophthalmology; 1998:1-269.

2. Babar TF, Masud Z, Saeed N, Khan MD. An analysis of patients with chronic dacryocystitis. Pak J Ophthalmol 2003;19(3):77-83.

3. Dalgleish R. Idiopathic acquired lacrimal drainage obstruction. Br J Ophthalmol 1967;51(7):463-68.

4. Bharathi MJ, Ramakrishnan R, Maneksha V, Shivakumar C, Nithya V, Mittal S. Comparative bacteriology of acute and chronic dacryocystitis. Eye 2008;22(7):253-60.

5. Chaudhary M, Bhattarai A, Adhikari SK, Bhatta DR. Bacteriology and antimicrobial susceptibility of adult chronic dacryocystitis. Nepal J Ophthalmol 2010;2(4):105-13. 
6. Cahill KV, Burns JA. Management of acute dacryocystitis in adults. Ophthal Plast Reconstr Surg 1993;9:38-41.

7. Massaro BM, Gonnering RS, Harris GJ. Endonasal laser dacryocystorhinostomy. A new approach to nasolacrimal duct obstruction. Arch Ophthalmol 1990;108:1172-76.

8. Woog JJ, Metson R, Puliafito CA. Holmium YAG endonasal laser dacryocystorhinostomy. Am J Ophthalmol 1993;116: 1-10.

9. Lee TS, Woog JJ. Endonasal dacryocystorhinostomy in the primary treatment of acute dacryocystitis with abscess formation. Ophthal Plast Reconstr Surg 2001;17:180-83.

10. Duggal P, Mahindroo NK, Chauhan A. Primary endoscopic dacryocystorhinostomy as treatment for acute dacryocystitis with abscess formation: Am J Otolaryngol Head Neck Med Surg 2008;29:177-79.

11. Wu W, Yan Y, MacCallum JK, Tu Y, Jiang AC, Yang Y, et al. Primary treatment of acute dacryocystitis by endoscopic dacryocystorhinostomy with silicone intubation guided by a soft probe. Ophthalmology 2009 Jan;116(1):116-22.

12. Morgan S, Austin M, Whittet H. The treatment of acute dacryocystitis using laser assisted endonasal dacryocystorhinostomy. Br J Ophthalmol 2004;88:139-41.

13. Presutti L. Endonasal dacryocystorhinostomy. Acta Otorhinolaryngol Ital 1995;15:449-53.

14. Maheshwari R, Maheshwari S, Shah T. Acute dacryocystitis causing orbital cellulitis and abscess. Orbit 2009;28(2-3): 196-99.

15. Hartikainen J, Grenman R, Puukka P, Seppa H. Prospective randomized comparison of external dacryocystorhinostomy and endonasal laser dacryocystorhinostomy. Ophthalmology 1998;105:1106-13.

16. Coden DJ, Hornblass A, Haas BD. Clinical bacteriology of dacryocystitis in adults. Ophthal Plast Reconstr Surg 1993;9: 125-31.

17. Kupper DS, Demarco RC, Resende R, et al. Endoscopic nasal dacryocystorhinostomy: Results and advantages over external approach. Rev Bras Otorrinolaringol (Engl Ed) 2005;71(3): 356-60.

18. El-Guindy A, Dorgham A, Ghoraba M. Endoscopic revision surgery for recurrent epiphora occurring after external dacryocystorhinostomy. Ann Otol Rhinol Laryngol 2000;109:430-35.

19. Allen KM, Berlin AJ. Dacryocystorhinostomy failure association with nasolacrimal silicone intubation. Ophthalmic Surg 1982;20:486-89.

20. Walland MJ, Rose G. The effect of silicone intubation on failure and infection rates after dacryocystorhinostomy. Ophthalmic Surg 1994;24:597-600.

21. Subbaiah S. Role of endoscopic dacryocystorhinostomy in treating acquired lacrimal fistulae. J Laryngol Otol 2003 Oct;117(10):793-95.

22. Sodhi PK, Pandey RM, Malik KP. Experience with bicanalicular intubation of the lacrimal drainage apparatus combined with conventional external dacryocystorhinostomy. J Craniomaxillofac Surg 2003;31:187-90.

23. McLavhlan DL, Sahannon GM, Flanagan JC. Results of dacryocystorhinostomy. Ophthalmic Surg 1980;11:427-30.

24. Quickert MH, Dryden RM. Probes for intubation in lacrimal drainage. Ophthalmol Plas Reconstr Surg 1970;74:431-33.

25. Veirs ER. Lacrimal disorders, diagnosis and treatment. St Louis: CV Mosby Co 1976:130-31.

\section{ABOUT THE AUTHORS}

\section{Sudhir M Naik (Corresponding Author)}

Associate Professor, Department of ENT and Head and Neck Surgery KVG Medical College and Hospital, Sullia, Kurunjibag-574327 Karnataka, India, Phone: 09916807109, e-mail: sud223@gmail.com

\section{Sarika S Naik}

Senior Resident, Department of Anesthesia, Narayana Hrudayalaya Bengaluru, Karnataka, India 